June -2017

\title{
Student Perceptions of College Faculty Who Use OER
}

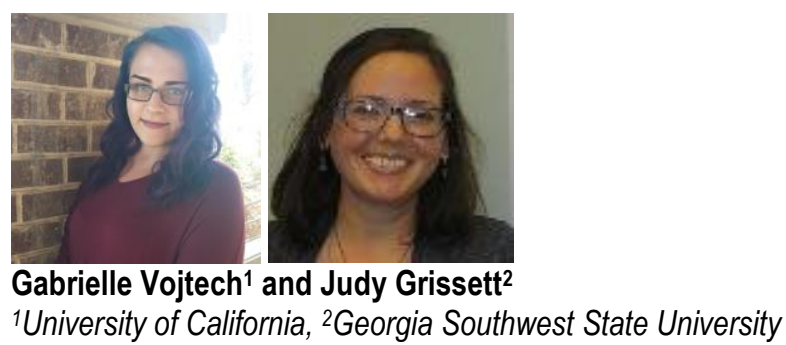

\begin{abstract}
Research indicates that students find open educational resources (OER) favorable, but there is no research regarding students' perceptions of faculty who use open textbooks. In the present study we examined this topic experimentally with two undergraduate psychology courses at a small public university. Participants read two passages-one about an instructor using an open textbook and another using a traditional copyrighted textbook-and rated each instructor on a range of characteristics through closed- and open-ended questions. Participants rated faculty using an open textbook higher on kindness, encouragement, and creativity than faculty using a traditional copyrighted textbook, and were more likely to want to take a class with faculty using an open textbook. Participants frequently mentioned textbook cost in their justifications.
\end{abstract}

Keywords: open educational resources, OER, college students, students' perceptions of college faculty

\section{Student Perceptions of College Faculty Who Use OER}

Current research on the topic of open educational resources (OER) in higher education is in its roots, in part because OER are relatively new in education. The term OER was only adopted by UNESCO in 2002 at a forum on the Impact of Open Courseware for Higher Education in Developing Countries (Johnstone, 2005). Still, there has been a recent swell of interest and empirical investigation surrounding OER in the past decade. Much of the research to date focuses on the efficacy and cost savings of OER, or the attitudes students and faculty have towards these materials (e.g., Bliss, Hilton, Wiley, \& Thanos, 2013; Bliss, Robinson, Hilton, \& Wiley, 2013; Hilton, Gaudet, Clark, Robinson, \& Wiley, 2013; Hilton, Robinson, Wiley, \& Ackerman, 2014; Lindshield \& Adhikari, 2013). However, research has not addressed, in depth, students' attitudes toward the faculty who use open materials. The purpose of the present study is to bridge this gap in the literature by conducting an experiment on how students perceive college faculty who use open materials. 


\section{Review of the Literature}

OER encompass a diverse range of learning materials, from full courses to pedagogical techniques (William and Flora Hewlett Foundation, n.d.). At their core, OER provide educators with the flexibility of choosing their own materials while providing substantial financial savings to students. In fact, the key characteristics of OER have been dubbed the 5 Rs: Retain, Reuse, Revise, Remix, and Redistribute (Wiley, n.d.), further describing the flexibility OER provide to users.

In this section we highlight literature on OER efficacy, cost savings, and student perceptions of OER. In addition to our summary below, a recently published manuscript by Hilton (2016) provides a thorough review of 16 empirical manuscripts about the impact of OER on student learning and perceptions of OER. Given our research question about student perceptions of faculty who use OER, we also discuss factors that influence student perceptions of faculty.

\section{Student Performance and Efficacy of OER}

The majority of the literature surrounding the efficacy of open textbooks shows student performance during or after the use of an open textbook is equivalent to student performance during or after the use of a traditional copyrighted textbook. Hilton et al. (2013) found no notable difference in student passing rates in most courses in the year open textbooks were used compared to previous years when traditional copyrighted textbooks were used. Similarly, Wiley, Hilton, Ellington, and Hall (2012) found no change in student performance on the annual standardized test known as the Criterion-Referenced Tests (CRT) when traditional copyrighted textbooks were replaced with open textbooks. Bowen, Chingos, Lack, and Nygren (2012) found no differences between students using a hybrid textbook (comparable to an open textbook in this study) and those using a traditional, copyrighted textbook on passing rates, scores on the Comprehensive Assessment of Outcomes in First Statistics Courses (CAOS), and final exam scores.

When differences have been found in student performance, better course outcomes have typically favored OER-users. Lovett, Meyer, and Thille (2008) found students using an open textbook showed a significant gain in scores on the CAOS test when compared to students using a traditional copyrighted textbook in the same course. In a second study, students using an open textbook performed similarly to those using a traditional copyrighted textbook when given only half as much time as students using a traditional copyrighted textbook to learn the material.

Fischer, Hilton, Robinson, and Wiley (2015) completed one of the largest studies on this topic, with over 16,000 participating students at ten United States institutions. They looked at three different measures of student success to determine the efficacy of an open textbook: course completion, completion with a grade of C- or better, and course grade. Students in most courses maintained the same average of completion with a C- or better. However, students in five of the fifteen courses using the open textbook surpassed the control group's average of completion with a C- or better. Ten of the courses showed no significant difference in final course grade, but four of the courses showed higher grades for students using the open textbook compared to students using the traditional copyrighted textbook. 
Many smaller scale studies suggest the use of open materials does no harm, at worst (Bowen et al., 2012; Hilton et al., 2013; Wiley et al., 2012). The largest study, using multiple measures, found students performed better in some courses when assigned an open textbook compared to when assigned a traditional copyrighted textbook (Fischer et al., 2015). It would be appropriate to deduce, at best, that OER are beneficial to students.

\section{Cost Savings of OER}

Higher education is becoming increasingly expensive, creating a financial burden for students and their families. As reported in The College Board's Trends in Higher Education, the cost of tuition and fees at a public four-year institution is "40\% higher, after adjusting for inflation, in 2015-16 than it was in 2005o6” (Ma, Baum, Pender, \& Bell, 2015, p. 3). Moreover, the U.S. Government Accountability Office (2005) found that the cost of textbooks alone had risen at two times the annual inflation rates. This textbook inflation has become a problem for many students, as textbooks are often not included in the cost of tuition and fees. In a study by Bliss et al. (2013b), over 80 percent of students reported they often or always purchase the required text for their courses, and over 80 percent of the same students reported spending over $\$ 200$ on these texts each semester. In another study the cost savings for students at a university would be greater than $\$ 1$ million if only five percent of the student population used an open textbook rather than a traditional copyrighted textbook (Hilton et al., 2014).

In a comprehensive study of cost savings in a K-12 environment, Wiley et al. (2012) compared the cost of developing an open textbook to the cost of purchasing a copyrighted textbook. The cost of an open textbook was determined by combining printing costs, the amount paid to teachers for training, and the estimated value of the unpaid time teachers spent developing the open textbook. The cost of the open textbook was higher than the traditional copyrighted textbook the first year of implementation, but when these factors were controlled for during the second year, the cost of the open textbook was lower. Over a period of seven years, the school district of 10,000 students would save approximately $\$ 1,761,200$ by adopting the open textbook.

Textbook cost goes beyond financial burden. If students are not able to purchase a required text, this may have a large effect on the extent of their learning capabilities in the course (Landrum, Gurung, \& Spann, 2012). This is one of the most compelling arguments in favor of open textbooks, since many studies have shown open textbooks are equivalently, or more, effective than their traditional copyrighted counterparts.

\section{Perceptions of OER}

Student perceptions. Student perceptions of learning materials have been linked to student engagement and, ultimately, reading comprehension and achievement (Guthrie \& Wigfield, 200o). Additionally, if students do not feel engaged or do not enjoy the text, they are likely to not read it (Landrum et al., 2012). For this reason, student perceptions of open materials are a common topic of discussion in the field of OER. 
One study showed that of 490 students who had used an open textbook the previous semester, seven percent perceived the open textbook as worse quality than a previously used copyrighted textbook. In all of these cases, participants cited technological issues or poor quality of the information presented in the text (Bliss et al., 2013a). On the other hand, 39\% found the open textbook to be of better quality than the previously used traditional copyrighted textbook. In another study, Hilton et. al. (2013) focused on the use of open textbooks in five mathematics classes at a community college. Of 966 students who participated in the survey, 83 percent either agreed or slightly agreed with the statement "Overall, the materials adequately supported the work I did in class." and 82 percent of responses to the question "What additional comments do you have regarding the quality of the open materials used in your class?" were positive.

These studies show a large majority of students tolerate open materials, at worst. At best, students seem to think well of the open materials presented to them. However, not all open textbooks are of the same quality and further research is needed to better understand student perception of open textbooks using different variables and across disciplines.

Faculty perceptions. Faculty perceptions of course materials have a large impact on the quality of the courses they teach. This is one reason faculty perceptions of open materials is a common topic of discussion in the field of OER. For example, of 20 instructors surveyed, only three rated the open materials as worse quality than previously used traditional copyrighted textbooks. Thirteen of the twenty instructors claimed the open materials adequately supported the work they did in class (Hilton et al., 2013). In another study, 30 middle and high school teachers rated the open/adapted textbooks 38 percent higher in quality than the traditional copyrighted textbooks (Kimmons, 2015).

In sum, open textbooks presented to faculty members, on average, received higher quality ratings than the traditional copyrighted textbooks. The literature also suggests that faculty members prefer open textbooks that they are able to adapt to their teaching styles.

\section{Students' Perceptions of Faculty}

This section will address two questions: (1) What qualities do students attribute to effective teachers? and (2) Does considering a teacher effective have any impact on a student's course performance?

In terms of the first question, Ralph (2003) identified five features of effective instructors: commitment to learners, knowledge of material, organization and management of the environment, desire to improve, and collaboration with others. In a study by Delaney, Johnson, Johnson, and Treslan (2010), students reported nine attributes of an effective teacher: respectful, knowledgeable, approachable, engaging, communicative, organized, responsive, professional, and humorous. The personal characteristic of caring, falling under the category of respectful, was a repeated theme. Students indicated that caring instructors were those who displayed interest in them and their well-being. Professors' concern for student success, also categorized under respectful, was another common theme.

These findings are not new. Reports of characteristics that make for effective instructors today are similar to those found throughout recorded history, including accessibility and approachability, fairness, open- 
mindedness, mastery and delivery, enthusiasm, humour, and knowledge and inspiration imparted (Axelrod, 2008). Students perceive effective teachers to be those who are involved in the learning process, seek to create trusting relationships with students, and provide flexible, yet structured, learning environments (Young, 2006).

Overall, students believe that effective instructors are those who are knowledgeable about the subject material, have a desire to improve their teaching abilities, engage their students, and provide flexible learning environments. They are organized, respectful, approachable, communicative, professional, humorous, and fair. Most importantly, they care about their students.

Students' perceived characteristics of effective faculty can have an effect on course performance. Caring teachers are able to promote and maintain student interest and cooperation more-so than non-caring teachers are, and students' perceptions of their teachers' levels of caring may have an influence on their level of engagement and seeking help with their school related struggles (Phelan, Davidson, \& Thanh Cao, 1992). Montalvo and Roedel (1995) found that students tend to want to please teachers who showed a desire to help students, provided positive feedback, went out of their way to be nice, showed respect for students, and spaced out the workload in order to decrease student stress. Students indicated that when they liked a teacher their quality of work, and effort put into their work, increased. In one study students did in fact earn higher grades in such classes and had higher levels of learning goals in general, such as a desire to seek post-secondary education (Montalvo, Mansfield, \& Miller, 2007).

In summary, student performance during and after the use of an open textbook is equivalent to, and in some cases higher than, student performance during and after the use of a traditional copyrighted textbook. Studies have repeatedly shown that replacing traditional copyrighted textbooks with open textbooks would result in significant cost savings for the schools and students. Both students and faculty typically rate open textbooks similarly or better than traditional copyrighted textbooks. Lastly, students have higher course performance, among other things, when they favour the instructor and materials used in the course. The culmination of this information has, in the past, been used asevidence to argue that open textbooks are a better option than traditional copyrighted textbooks.

\section{Current Study}

Although we know that students indicate preference for certain characteristics in their teachers, and they perform better when teachers display those characteristics, there is not extensive research regarding students' perceptions of faculty members who choose to use open textbooks in their courses. The present research is a small, exploratory study that more closely examines this subject. Our research question asks if there is a difference between perceptions that students have of faculty members who use open textbooks and faculty members who use traditional copyrighted textbooks. We hypothesized that students would perceive the use of the open textbooks as a positive characteristic of faculty members. 


\section{Method}

\section{Participants}

The current study was conducted at a small, regional public university. Participants consisted of 23 students from two upper-level psychology courses. Participants in the two courses made use of a traditional copyrighted textbook rather than an open textbook, as to minimize the possible bias of students currently using an open textbook. Of the 23 surveys collected, one survey was removed from the study due to incomplete answers. Demographic information of the participants was not collected because these details were not at the focus of the current study. Participation was optional, and students were offered a modest amount of extra credit in the course for their participation.

\section{Materials}

Participants read two written passages about a college faculty member called "Dr. Wilson." In one passage that participants read, Dr. Wilson used a traditional copyrighted textbook, and in another passage s/he used an open textbook (Appendix). All participants read two passages, and passages were counterbalanced so that some participants read the passage about Dr. Wilson using the traditional copyrighted textbook first followed by the passage about him/her using the open textbook (and vice versa).

In order to minimize the effect of possible confounding variables, we varied the length of time the faculty member had been teaching at the university (either five or 25 years) and the gender of the faculty member (either male or female). This was done randomly, and served the purpose of eliminating bias against gender or experience. Length of time teaching, gender, and textbook type were controlled within participants so that each participant received a set of two passages about a faculty member with the same teaching experience and gender. For example, a participant who read about Dr. Wilson as female with five years of teaching experience who was using a traditional textbook would read a second passage about Dr. Wilson as female with five years of teaching experience who was using an open textbook. Passages were counterbalanced across participants. See Appendix for sample passages.

After reading each passage about Dr. Wilson, participants were then asked to rate the faculty member on a five-point Likert scale, on six personal characteristics: kindness, knowledgeability, enthusiasm, patience, encouragement, and creativity. Following each Likert scale rating, participants were given the opportunity to justify their ratings with an open-ended response ("On what basis did you make your judgment?”). Questions that followed each passage can be seen in Appendix.

Following the personal characteristic ratings, participants were asked to rate, on a five-point Likert scale, how likely they would be to take a class with the faculty member from the passage. They were given the option to justify their rating through an open-ended response, just as with the questions regarding personal characteristics. 


\section{Procedure}

The passages and questionnaires were administered through paper and pencil. The study materials were handed out at the beginning of each of the class periods, and participants were then given adequate time to complete the study. This took approximately twenty minutes for participants to complete. After the study materials were administered and completed, the instructor collected them from participants.

\section{Results}

Recall that participants were asked to rate the professors on six characteristics (kindness, knowledgeability, enthusiasm, patience, encouragement, and creativity) on a five-point Likert scale, as well as how likely they would be to take a course with each professor (also rated on a five-point Likert scale). Participants were then asked to provide a justification for their response to each question ("On what basis did you make your judgment?”).

\section{T-test Results}

In our analyses, we first compared the mean rating scores on each of the seven Likert-scale questions, comparing participants' perceptions of the two faculty members. These analyses were done through independent samples t-tests, with lower scores reflecting stronger opinions (e.g., "Very kind;" "Very knowledgeable"). The results of these t-tests can be seen in Table 1.

Table 1

Students' Perceptions of Faculty Using Traditional and Open Textbooks

\begin{tabular}{|l|l|l|l|l|l|l|l|}
\hline & \multicolumn{2}{|c|}{ Mean } & \multicolumn{2}{c|}{ Std. Deviation } & \multicolumn{3}{c|}{} \\
\hline & Traditional & Open & Traditional & Open & $t$ & $d f$ & $\begin{array}{c}\text { Sig (2- } \\
\text { tailed) }\end{array}$ \\
\hline Kindness & 2.217 & 1.522 & .9512 & .7903 & -2.697 & 44 & 0.010 \\
\hline Knowledgeability & 1.565 & 1.435 & .8435 & .5898 & -0.608 & 44 & 0.546 \\
\hline Enthusiasm & 1.609 & 1.304 & .7827 & .5588 & -1.518 & 44 & 0.136 \\
\hline Patience & 2.609 & 2.217 & .8913 & .7952 & -1.571 & 44 & 0.123 \\
\hline Encouragement & 2.26 & 1.73 & .964 & .767 & -2.049 & 43 & 0.047 \\
\hline Creativity & 2.26 & 1.55 & 1.137 & .800 & -2.431 & 43 & 0.019 \\
\hline $\begin{array}{l}\text { Likelihood of taking } \\
\text { course }\end{array}$ & 2.70 & 1.59 & 1.363 & .959 & -3.131 & 43 & 0.003 \\
\hline
\end{tabular}

Note. Lower mean scores denote a stronger opinion about each quality.

Our results revealed that participants rated faculty using an open textbook as being more kind, $t(44)=$ 2.697, $p=.01$, encouraging, $t(43)=-2.049, p=.047$, and creative, $t(43)=-2.431, p=.019$. Participants were more likely to want to take a course with that faculty member than one using a traditional textbook, $t(43)=-3.131, p=.003$. These differences held even after controlling for faculty gender and length of time teaching at the university. 


\section{Participants' Justifications for Perceptions of Faculty}

After analyzing participants' ratings on each characteristic, we analyzed participants' justifications for why they provided the response they did (“On what basis did you make your judgment?"). We first coded each response using an open-coding process, which allowed 17 codes to emerge. These initial codes are listed in Table 2.

Table 2

Emergent Codes of Participants' Justifications for Perceptions of Faculty

\begin{tabular}{|l|l|}
\hline \multicolumn{2}{|l|}{$\quad$ Initial Codes Key } \\
\hline 1 & Not enough information provided \\
\hline 2 & Seems to enjoy job \\
\hline 3 & Makes an effort to benefit students/catering to student needs/wants student to succeed \\
\hline 4 & Has experience as a professor/has been teaching for 5 or 25 years \\
\hline 5 & Has a variety of teaching techniques \\
\hline 6 & The way they teach \\
\hline 7 & Enjoy teaching style \\
\hline 8 & If the class was necessary/required \\
\hline 9 & Similar to most college classes \\
\hline 10 & Just seems to be that way/no reason to believe otherwise \\
\hline 11 & No empathy for students \\
\hline 12 & No experience/not professional \\
\hline 13 & Expensive book/not considering student costs \\
\hline 15 & Inexpensive book/considering student costs \\
\hline 16 & Makes/wants to make changes to the textbook \\
\hline NA & Cannot make changes to the textbook \\
\hline
\end{tabular}

Upon reviewing the initial codes, we next collapsed the ones that were most similar into seven main themes (Table 3).

Table 3

Main Themes of Participants'Justifications for Perceptions of Faculty

\begin{tabular}{|l|l|l|}
\hline \multicolumn{2}{|c|}{ Themes } & \multicolumn{1}{c|}{ Initial Codes } \\
\hline A & Personal Characteristics - Positive & $\begin{array}{l}\text { Seems to enjoy job } \\
\text { Makes an effort to benefit students (etc.) } \\
\text { Has experience as a professor }\end{array}$ \\
\hline B & Personal Characteristics - Negative & $\begin{array}{l}\text { No empathy for students } \\
\text { No experience/not professional }\end{array}$ \\
\hline C & Teaching Styles & $\begin{array}{l}\text { Has a variety of teaching techniques } \\
\text { The way they teach } \\
\text { Enjoy teaching style }\end{array}$ \\
\hline D & Course Qualities & $\begin{array}{l}\text { If the class was necessary/required } \\
\text { Similar to most college classes }\end{array}$ \\
\hline E & Textbook Cost as a Factor - Positive & $\begin{array}{l}\text { Inexpensive book/considering student costs } \\
\text { Makes/wants to make changes to the textbook }\end{array}$ \\
\hline F & Textbook Cost as a Factor - Negative & Expensive book/not considering student costs \\
\hline
\end{tabular}




\begin{tabular}{|l|l|l|}
\hline & & Cannot make changes to the textbook \\
\hline $\mathrm{G}$ & Other & $\begin{array}{l}\text { Not enough information provided } \\
\text { Just seems to be that way/no reason to believe otherwise }\end{array}$ \\
\hline
\end{tabular}

Our next step was to examine the data using the seven main themes that emerged through our coding process. We were looking for trends in participants' justifications for their ratings on the six faculty characteristics and whether they would take a course with that faculty member. Each participant had the opportunity to give 14 total open ended replies (seven for the passage regarding an open textbook; seven for the passage regarding traditional copyrighted textbook).

Our coding analysis was not mutually exclusive, so participant replies may have been labeled with more than one code. After making note of the answers that had more than one code and those that were left blank, there were 319 total responses. Note that this total is inclusive of all codes given by all participants for the 14 open ended replies. Upon reviewing all of the responses, we found that, out of 319 responses, positive personal characteristics $(n=107)$, teaching styles $(n=76)$, and textbook cost ( $n_{\text {positive }}=44 ; n_{\text {negative }}$ $=23$ ) were mentioned most frequently as reasons why they rated the faculty members as they did (Table 4). Another 57 responses (17.9\%) were coded as “Other." Questions left unanswered were omitted from the analysis.

Table 4

Tally of Responses Broken Down by Question

\begin{tabular}{|c|c|c|c|c|}
\hline & \multicolumn{2}{|c|}{ Textbook Type } & \multirow[b]{2}{*}{$\begin{array}{c}\text { Open } \\
\text { (\# of responses) }\end{array}$} & \multirow[b]{2}{*}{$\begin{array}{c}\text { Total } \\
\text { (\# of responses) }\end{array}$} \\
\hline Characteristic & Theme & $\begin{array}{c}\text { Traditional } \\
\text { (\# of responses) }\end{array}$ & & \\
\hline \multirow[t]{8}{*}{ All Characteristics } & $\mathrm{A}$ & 50 & 57 & 107 \\
\hline & $\mathrm{B}$ & 1 & 2 & 3 \\
\hline & $\mathrm{C}$ & 38 & 38 & 76 \\
\hline & $\mathrm{D}$ & 6 & 3 & 9 \\
\hline & $\mathrm{E}$ & 4 & 40 & 44 \\
\hline & $\mathrm{F}$ & 23 & $\mathrm{O}$ & 23 \\
\hline & $\mathrm{G}$ & 34 & 23 & 57 \\
\hline & & & Total & 319 \\
\hline \multirow[t]{8}{*}{ Kindness } & A & 4 & 6 & 10 \\
\hline & B & 0 & 0 & 0 \\
\hline & $\mathrm{C}$ & 6 & 4 & 10 \\
\hline & $\mathrm{D}$ & 0 & 0 & 0 \\
\hline & $\mathrm{E}$ & 2 & 9 & 11 \\
\hline & $\mathrm{F}$ & 4 & $\mathrm{O}$ & 4 \\
\hline & G & 6 & 4 & 10 \\
\hline & & & Total & 45 \\
\hline \multirow[t]{7}{*}{ Knowledgeability } & $\mathrm{A}$ & 17 & 15 & 32 \\
\hline & $\mathrm{B}$ & 1 & 2 & 3 \\
\hline & $\mathrm{C}$ & $\mathrm{O}$ & 2 & 2 \\
\hline & $\mathrm{D}$ & 0 & 0 & 0 \\
\hline & $\mathrm{E}$ & 0 & 2 & 2 \\
\hline & $\mathrm{F}$ & 2 & 0 & 2 \\
\hline & $\mathrm{G}$ & 2 & 1 & 3 \\
\hline
\end{tabular}




\begin{tabular}{|c|c|c|c|c|}
\hline & & & Total & 44 \\
\hline \multirow[t]{8}{*}{ Enthusiasm } & $\overline{\mathrm{A}}$ & 13 & 12 & 25 \\
\hline & B & 0 & 0 & 0 \\
\hline & $\mathrm{C}$ & 5 & 9 & 14 \\
\hline & $\mathrm{D}$ & 0 & 0 & 0 \\
\hline & $\mathrm{E}$ & 1 & 1 & 2 \\
\hline & $\mathrm{F}$ & 1 & 0 & 1 \\
\hline & $\mathrm{G}$ & 3 & 1 & 4 \\
\hline & & & Total & 47 \\
\hline \multirow[t]{8}{*}{ Patience } & A & 4 & 5 & 9 \\
\hline & $\mathrm{B}$ & 0 & 0 & $\mathrm{O}$ \\
\hline & $\mathrm{C}$ & 3 & 2 & 5 \\
\hline & $\mathrm{D}$ & 0 & 0 & 0 \\
\hline & $\mathrm{E}$ & 0 & 5 & 5 \\
\hline & $F$ & 1 & 0 & 1 \\
\hline & $\mathrm{G}$ & 14 & 10 & 24 \\
\hline & & & Total & 44 \\
\hline \multirow[t]{8}{*}{ Encouragement } & $\mathrm{A}$ & 7 & 10 & 17 \\
\hline & B & 0 & 0 & 0 \\
\hline & $\mathrm{C}$ & 6 & 7 & 13 \\
\hline & $\mathrm{D}$ & $\mathrm{O}$ & O & $\mathrm{O}$ \\
\hline & $\mathrm{E}$ & $\mathrm{O}$ & 2 & 2 \\
\hline & $\mathrm{F}$ & 2 & 0 & 2 \\
\hline & G & 7 & 4 & 11 \\
\hline & & & Total & 45 \\
\hline \multirow[t]{8}{*}{ Creativity } & A & 1 & 0 & 1 \\
\hline & $\mathrm{B}$ & $\mathrm{O}$ & 0 & 0 \\
\hline & $\mathrm{C}$ & 13 & 10 & 23 \\
\hline & $\mathrm{D}$ & 0 & 0 & 0 \\
\hline & $E$ & 1 & 12 & 13 \\
\hline & $\mathrm{F}$ & 7 & 0 & 7 \\
\hline & $\mathrm{G}$ & 0 & 1 & 1 \\
\hline & & & Total & 45 \\
\hline \multirow[t]{8}{*}{ Likelihood of Taking a Course } & $\mathrm{A}$ & 4 & 9 & 13 \\
\hline & $\mathrm{B}$ & $\mathrm{O}$ & 0 & $\mathrm{O}$ \\
\hline & $\mathrm{C}$ & 5 & 4 & 9 \\
\hline & $\mathrm{D}$ & 6 & 3 & 9 \\
\hline & $\mathrm{E}$ & 0 & 9 & 9 \\
\hline & $\mathrm{F}$ & 6 & 0 & 6 \\
\hline & G & 2 & 2 & 4 \\
\hline & & & Total & 50 \\
\hline
\end{tabular}

Note. $\mathrm{A}=$ Personal Characteristics- Positive; $\mathrm{B}=$ Personal Characteristics- Negative; $\mathrm{C}=$ Teaching Styles; $\mathrm{D}=$ Course Qualities; E = Textbook Cost- Positive; F = Textbook Cost- Negative; $\mathrm{G}=$ Other

As can be seen in Table 4, "positive personal characteristics" ( $n=107)$ was the top justification participants gave for why they rated the professors as they did for the following characteristics: kindness $(n=10)$, knowledgeability $(n=32)$, enthusiasm $(n=25)$, encouragement $(n=17)$, and likelihood to take a course with that professor $(n=13)$. For example one participant who rated the professor using an open textbook as showing "a lot of encouragement" explained that, "Her enjoyment and enthusiasm from her job seems very encouraging for her students." Of the responses coded as "positive personal characteristics," most were related to the experience level of the faculty member $(n=51)$. Other responses 
for this code indicated that the faculty member made an effort to benefit students $(n=38)$ and seemed to enjoy their job $(n=25)$.

The second most common justification was "teaching styles" $(n=76)$, with it being the top justification for creativity $(n=23)$ and commonly mentioned for kindness $(n=10)$, enthusiasm $(n=14)$, and encouragement $(n=13)$. For example one participant who rated the professor using the traditional textbook as "very kind" stated that, "She appeals to different types of learners." Another who rated the professor using an open textbook as "very enthusiastic" stated, "He takes extra time to prepare in different ways." A third who rated the professor using a traditional textbook as giving "a lot of encouragement" stated, "She uses many methods to help the students."

Although not a top justification, "textbook cost - positive" was of particular relevance to our research topic and was mentioned in 44 responses. It was provided the most to justify participants' perceptions of the professors' levels of kindness ( $n=11)$, and creativity $(n=13)$, and participant likelihood of taking a course with the professor $(n=9)$. For example one participant who rated the professor using an open textbook as "very kind" stated, "She offers an alternate, more financially friendly form of the textbook that is free." Another participant who rated the professor using an open textbook as "very kind" stated that he was "easier on his students' wallets." One participant who rated the professor as giving "a lot of encouragement" stated that, "He finds them books for free." The same participant said he or she was very likely to take a course with the professor, explaining that he offered "cheap books" and "seems nice."

There were a few notable differences between participants' justifications for ratings of faculty members using open versus traditional textbooks in terms of textbook cost. In total, more "textbook cost - positive" justifications were provided for the faculty member using an open textbook $(n=40)$ versus a traditional copyrighted textbook $(n=4)$. "Textbook cost - positive" responses were provided more often as justification for the rating of creativity for professor using the open textbook $(n=12)$ compared to the traditional copyrighted textbook $(n=1)$. It was also used more often to justify the likelihood of taking a course for faculty members using an open textbook $(n=9)$ compared to a traditional copyrighted textbook $(n=0)$. Related, more "textbook cost - negative" justifications were provided for the faculty member using a traditional copyrighted textbook $(n=23)$ versus an open textbook $(n=0)$.

Finally, many participants mentioned that not enough information was provided or there was no reason to believe otherwise. These responses were categorized as "other" and were most commonly reported in response to questions about kindness and patience. For example, "Not enough information has been given in the article to determine this," was given in regards to the level of patience of a professor using an open textbook. Another response stated, in regards to the level of kindness of a professor using a traditional textbook, "Didn't read anything that says she isn’t."

\section{Discussion}

In the present study we examined college students' perceptions of faculty who use open versus traditional copyrighted textbooks. Twenty-three participants read short passages about two college faculty 
members-one open textbook-user and one traditional textbook-user-and rated them on several characteristics: kindness, knowledgeability, enthusiasm, patience, encouragement, and creativity, and how likely they are to want to take a course with each professor. Independent t-test results showed that participants rated the faculty member using an open textbook as more kind, encouraging, and creative than the faculty member using a traditional copyrighted textbook, and that participants would be more likely to take a course with a faculty member using an open textbook than a course with a faculty member using a traditional copyrighted textbook.

Participants also provided justifications for their responses. These responses were coded and tallied for each characteristic and whether the faculty member was using an open or traditional textbook. "Positive personal characteristics" was the most frequently mentioned justification, followed by "teaching styles." Textbook cost was another frequently listed justification. Of interest, "textbook cost as a positive factor" was listed more for faculty using an open textbook than those using a traditional textbook, whereas "textbook cost as a negative factor" was listed more for faculty using a traditional textbook than open textbook. Students found faculty members who use open textbooks to be similarly knowledgeable to faculty members using traditional copyrighted textbooks. However, faculty members who used the open textbook were seen as providing a more flexible learning environment (i.e., ability to make changes to the textbook; providing alternative methods of obtaining the material).

Prior research has also shown that a faculty member's level of caring or kindness is a major factor in students' perceptions of faculty member effectiveness (Phelan et al., 1992; Young, 2006). The current study found that students perceive faculty members who use open textbooks as more kind than faculty members who use traditional copyrighted textbooks. A commonly cited reason was the cost of the open textbook in comparison to the cost of the traditional copyrighted textbook.

Our findings are largely in line with previous literature on open materials, where faculty members rate open/adapted textbooks higher than both open and traditional copyrighted textbooks (e.g., Kimmons, 2015). Our findings suggest that students may prefer that faculty members have the option to adapt their open textbook, as many participants linked positive ratings with the faculty member's ability to make changes to the textbook in question. Likewise, participants linked negative ratings with the faculty member's inability to make changes to the textbook.

\section{Limitations and Future Directions}

There were several possible limitations of the present study. First, students may have used open textbook in the past, which could have altered their views about open materials and faculty who use these materials. Because we did not ask participants about their prior experience with open materials, it is unknown whether this played a role in their responses. It is also possible that past use of traditional copyrighted textbooks may have skewed their perception of such materials. However, since no data was collected on this, no conclusions can be made.

Second, there were only 23 participants and all were from two upper-level psychology courses. These two factors negatively impact generalizability and lessen external validity. Future studies may include more 
participants, as well as consider background demographic data to examine whether factors such as gender, age, or college major influence perceptions of faculty textbook use.

Third, participants did not read a control passage, but instead read two passages that varied on one factor-the type of textbook used. Because of this, it is possible that students were aware of the purpose of the study and exhibited demand characteristics, altering their responses based on their preconceptions about OER. Future research should include a control passage to which the results from the other two passages can be compared, as well as longer passages so that the purpose of the study is less clear to participants.

Fourth, the wording of the passages may have appeared biased in favor of open educational materials. For example, the open textbook passage used the wording "only \$30," to describe the price of purchasing a hard copy of the textbook. The use of "only," may have induced a bias in participants, since no equivalent term was used in the passage regarding traditional copyrighted textbooks. Another example is the wording of the last lines of each passage, indicating that faculty members using OER are able to make changes to the textbook while faculty members using traditional copyrighted textbooks cannot. This may have altered the participants' perceptions of faculty members, particularly in reference to the personal characteristic of creativity. The intention of this was to point out fundamental differences in how the textbooks may be used, but may have been misleading to participants.

Also, the price for the traditional copyrighted textbook may have not represented the average cost of a traditional copyrighted textbook for an Introduction to Psychology course. The number we used was drawn from Bliss et al. (2013b), where students reported spending nearly $\$ 200$ on required textbooks. Future studies may include a textbook cost determined to be average for the course used in the passage.

Lastly, although we used a combination of open and closed-ended questions, the results do not provide an in-depth picture of students' perceptions of faculty based on the textbook format they use. Future studies may employ a different set of research methodologies, including structured or semi-structured interviews with students or even analyses of teaching evaluations at the end of the semester. For example, it would be interesting to compare faculty teaching evaluations before and after using a set of open resources and compare those results to evaluations when using a traditional textbook. This sort of project would be a good fit in the growing body of scholarship of teaching and learning research.

\section{Conclusion}

Our study is the first to our knowledge that examined students' perceptions of college faculty based on their use of either an open or traditional copyrighted textbook through an experimental design. The findings have important implications for college faculty interested in adopting open textbooks. This is not to say that student perceptions should be a driving factor for textbook selection. Rather, faculty may want to know how their choice of textbook materials is perceived by their students. We hope this study will prompt further research into the impact of textbook selection on students' perceptions of college faculty. 


\section{References}

Axelrod, P. (2008). Student perspectives on good teaching: What history reveals. The Journal of Higher Education, 24-27.

Bliss, T. J., Hilton, J., III, Wiley, D., \& Thanos, K. (2013a). The cost and quality of open textbooks: Perceptions of community college faculty and students. First Monday, 18(1). http://dx.doi.org/10.5210/fm.v18i1.3972

Bliss, T. J., Robinson, T.J., Hilton, J., III, \& Wiley, D. (2013b). An OER COUP: College teacher and student perceptions of open educational resources. Journal of Interactive Media in Education, 2013(1). http://doi.org/10.5334/2013-04

Bowen, W., Chingos, M., Lack, K., \& Nygren, T. (2012). Interactive learning online at public universities: Evidence from randomized trials. ITHAKA.

Delaney, J., Johnson, A., Johnson, T., \& Treslan, D. (2010). Students' perceptions of effective teaching in higher education. St. John's, NL: Distance Education and Learning Technologies.

Fischer, L., Hilton, J., III, Robinson, T.J. \& Wiley, D. (2015). A Multi-institutional study of the impact of open textbook adoption on the learning outcomes of post-secondary students. Journal of Computing in Higher Education, 27(3), 159-172. doi:10.1007/s12528-015-9101-x

Guthrie, J., \& Wigfield, A. (2000). Engagement and motivation in reading. Handbook of Reading Research (3), 403-422.

Hilton, J., III (2016). Open educational resources and college textbook choices: A review of research on efficacy and perceptions. Educational Technology Research and Development, 64(4), 573-590. doi:10.1007/s11423-016-9434-9

Hilton, J., III, Gaudet, D., Clark, P., Robinson, T.J., \& Wiley, D. (2013). The adoption of open education resources by one community college math department. The International Review in Research of Open and Distributed Learning, 14(4). Retrieved from http://www.irrodl.org/index.php/irrodl/article/view/1523/2652

Hilton, J., III, Robinson, T.J., Wiley, D., \& Ackerman, J.D. (2014). Cost-savings achieved in two semesters through the adoption of open educational resources. The International Review of Open and Distributed Learning, 15(2). Retrieved from http://www.irrodl.org/index.php/irrodl/article/view/170o/2833

Johnstone, S. (2005). Open educational resources serve the world. Educause Quarterly, 28(3), 15-18.

Kimmons, R. (2015). OER quality and adaptation in K-12: Comparing teacher evaluations of copyrightrestricted, open, and open/adapted textbooks. The International Review of Open and Distributed Learning, 16(5), 39-57. 
Landrum, E., Gurung, R., \& Spann, N. (2012). Assessments of textbook usage and the relationship to student course performance. College Teaching, 6o(1), 17-24. doi:10.1080/87567555.2011.609573

Lindshield, B., \& Adhikari, K. (2013). Online and campus college students like using an open educational resource instead of a traditional textbook. MERLOT Journal of Online Learning and Teaching, $9(1), 26-38$.

Lovett, M., Meyer, O., \& Thille, C. (2008). The open learning initiative: Measuring the effectiveness of the OLI statistics course in accelerating student learning. Journal of Interactive Media in Education, 2008(1). http://doi.org/10.5334/2008-14

Ma, J., Baum, S., Pender, M., \& Bell, D. (2015). Trends in college pricing 2015. The College Board.

Montalvo, G. P., Mansfield, E. A., \& Miller, R. B. (2007). Liking or disliking the teacher: Student motivation, engagement and achievement. Evaluation \& Research in Education, 20(3), 144-158. doi:10.2167/eri406.0

Montalvo, G. P., \& Roedel, T. (1995). Pleasing the teacher: A qualitative look. Paper presented at the annual meeting of the American Educational Research Association, San Francisco, CA.

Phelan, P., Davidson, A., and Thanh Cao, H, (1992). Speaking up: Student perspectives on school. Phi Delta Kappan, 73(9), 695-704.

Ralph, E. G. (2003). Effective college teaching: Fresh insights and exemplary practices. New York: Nova Science.

United States Government Accountability Office. (2005). College textbooks: Enhanced offerings appear to drive recent price increases. Retrieved from http://www.gao.gov/new.items/d05806.pdf

Wiley, D. (n.d.). Defining the "open" in open content and open educational resources. Retrieved from http://opencontent.org/definition//

Wiley, D., Hilton, J., Ellington, S., \& Hall, T. (2012). A preliminary examination of the cost savings and learning impacts of using open textbooks in middle and high school science classes. The International Review of Open and Distributed Learning, 13(3). Retrieved from http://www.irrodl.org/index.php/irrodl/article/view/1153/2256

William and Flora Hewlett Foundation (n.d.). Open educational resources. Retrieved from http://www.hewlett.org/programs/education/open-educational-resources

Young, S. (2006). Student views of effective online teaching in higher education. The American Journal of Distance Education, 20(2), 65-77. http://dx.doi.org/10.1207/s15389286ajde2002 2 


\section{Appendix}

\section{Sample Passages Used to Describe Faculty Members Using a Traditional Copyrighted Textbook and Open Textbook, Followed by Open- and Closed-Ended Questions}

(Traditional copyrighted textbook)

Please read the passage and answer the following questions:

Professor Wilson is a psychology professor at Los Angeles State University. He has taught at this university for 5 years and enjoys his job very much. When teaching, he typically uses a mixture of PowerPoint presentations, videos, and homework assignments to help students better understand the material. This semester, Professor Wilson adopted a popular publisher's textbook for his Introduction to Psychology course. Students can purchase a hard copy of the text for $\$ 200$ or an electronic-copy for $\$ 175$. Overall, the textbook has received good reviews online and appears to help students better understand the material; however, because it is a publisher's textbook, Professor Wilson cannot make any changes to the textbook that he has adopted and must instead use the textbook "as-is."

(Open textbook)

Please read the passage and answer the following questions:

Professor Wilson is a psychology professor at Los Angeles State University. She has taught at this university for 25 years and enjoys her job very much. When teaching, she typically uses a mixture of PowerPoint presentations, videos, and homework assignments to help students better understand the material. This semester, Professor Wilson has adopted an open textbook for her Introduction to Psychology course. Students can download and use the textbook for free or purchase a hard-copy from the bookstore for only $\$ 30$. Overall, the textbook has received good reviews online and appears to help students better understand the material. Because it is an open textbook, Professor Wilson can make changes to the textbook as she sees fit in order to coincide with the lessons she is teaching.

Based on what you know about Professor Wilson...

How kind do you think Professor Wilson is? Very kind

Somewhat kind

Neutral

Somewhat unkind

Very unkind

On what basis did you make your judgment?

How knowledgeable about psychology do you think Professor Wilson is?

Very knowledgeable

Somewhat knowledgeable

Neutral

Somewhat unknowledgeable

Very unknowledgeable

On what basis did you make your judgment?

How enthusiastic do you think Professor Wilson is about psychology?

Very enthusiastic

Somewhat enthusiastic

Neutral

Somewhat unenthusiastic

Very unenthusiastic 
On what basis did you make your judgment?

How patient do you think Professor Wilson is?

Very patient

Somewhat patient

Neutral

Somewhat impatient

Very impatient

On what basis did you make your judgment?

How much encouragement do you think Professor Wilson shows his students?

A lot of encouragement

Some encouragement

Neutral

Some discouragement

A lot of discouragement

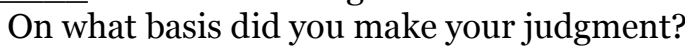

How creative do you think Professor Wilson is?

Very creative

Somewhat creative

Neutral

Somewhat uncreative

Very uncreative

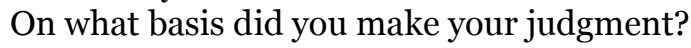

How likely would be to you take a course with Professor Wilson?

Very likely

Somewhat likely

Neutral

Somewhat unlikely

Very unlikely

On what basis did you make your judgment?

\section{Athabasca}

University

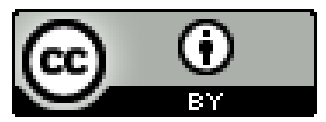

